\title{
natureouTLOoK STROKE
}

26 June 2014 / Vol 510 / Issue No 7506

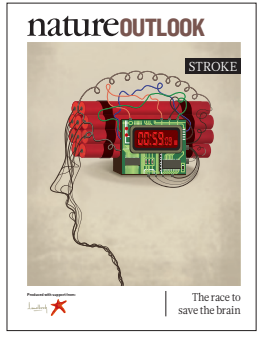

Cover art: Nik Spencer

\section{Editorial}

Herb Brody,

Michelle Grayson,

Brian Owens,

Anna York

Art \& Design

Wes Fernandes,

Mohamed Ashour,

Alisdair Macdonald,

Andrea Duffy

Production

Karl Smart,

Susan Gray,

lan Pope,

Christopher Clough

Sponsorship

Janice Stevenson,

Yvette Smith

Marketing

Hannah Phipps

Project Manager

Anastasia Panoutsou

Art Director

Kelly Buckheit Krause

Publisher

Richard Hughes

Magazine Editor

Rosie Mestel

Editor-in-Chief

Philip Campbell
$\mathrm{E}$ very year, strokes kill millions of people and leave millions more permanently disabled (page S2). They are terrifying ordeals that usually occur without warning - even though the causes are known (S4 and S12) - and rob people of their independence through impaired speech and movement. Researchers are trying to work out why the blood suddenly stops flowing smoothly to the brain, and how to limit and repair the resulting damage, thereby helping survivors to put their lives back together.

Treating stroke is a race against time: starved of oxygen, the brain cells die in the millions every minute. Doctors are therefore experimenting with mobile units that bring the hospital to the patient, drastically reducing the time it takes to deliver drugs that can limit the damage (S5).

Once a stroke has left its mark, the focus shifts to repair. One promising approach involves the use of hydrogels - polymers that can deliver treatments directly to the injured brain and stimulate and nurture the growth and differentiation of neural stem cells (S6).

Patients face a long road to recovery. But the months or years of physical therapy can be made less gruelling by incorporating the use of robotic helpers and other mechanical devices (S8).

For many people, however, physical recovery is the easy part. Strokes often result in depression, and it is becoming clear that this is not just because they are traumatic life events, but because they actually make the brain more susceptible to mood disorders. A topic of some controversy, therefore, is whether every patient should automatically receive antidepressants (S10).

We are pleased to acknowledge the financial support of Lundbeck in producing this Outlook. As always, Nature retains sole responsibility for all editorial content.

\section{Brian Owens}

Contributing Editor
Nature Outlooks are sponsored supplements that aim to stimulate interest and debate around a subject of interest to the sponsor, while satisfying the editorial values of Nature and our readers expectations. The boundaries of sponsor involvement are clearly delineated in the Nature Outlook Editorial guidelines available at go.nature.com/e4dwzw

CITING THE OUTLOOK

Cite as a supplement to Nature, for example, Nature Vol. XXX, No. XXXX Suppl., Sxx-Sxx (2014).

VISIT THE OUTLOOK ONLINE

The Nature Outlook Stroke supplement can be found at http://www. nature.com/nature/outlook/stroke

It features all newly commissioned content as well as a selection of

relevant previously published material.
All featured articles will be freely available for 6 months. SUBSCRIPTIONS AND CUSTOMER SERVICES For UK/Europe (excluding Japan): Nature Publishing Group, Subscriptions, Brunel Road, Basingstoke, Hants, RG21 6XS, UK. Tel: +44 (0) 1256329242 . Subscriptions and customer services for Americas - including Canada, Latin America and the Caribbean: Nature Publishing Group, 75 Varick St, 9th floor, New York, NY 10013-1917, USA. Tel: +18663637860 (US/Canada) or +1 212726 9223 (outside US/Canada). Japan/China/Korea: Nature Publishing Group - Asia-Pacific, Chiyoda Building 5-6th Floor, 2-37 Ichigaya Tamachi, Shinjuku-ku, Tokyo, 162-0843, Japan. Tel: +81 332678751. CUSTOMER SERVICES

Feedback@nature.com

Copyright $\odot 2014$ Nature Publishing Group

\section{COLLECTION}

S13 The worldwide burden of stroke - a blurred photograph B. Fuentes \& E. Dízz Tejedor

S15 Capillary pericytes regulate cerebral blood flow in health and disease C. N. Hall et al.

S21 Social interaction plays a critical role in neurogenesis and recovery after stroke

V. R. Venna et al.

\$30 Cerebral ischemic stroke: is gender important?

C. L. Gibson

S37 A large-sample assessment of possible association between ischaemic stroke and rs 12188950 in the PDE4D gene H. Lövkvist et al. 